\title{
Severe Symptomatic Hyponatremia Induced by Trimethoprim-Sulfamethoxazole
}

\author{
Maria Jose Velasco
}

\begin{abstract}
Trimethoprim-sulfamethoxazole (TMP-SMX) is a fixed-dose antimicrobial agent used in a variety of infections. Hyponatremia secondary to the syndrome of inappropriate secretion of antidiuretic hormone is an uncommon complication of treatment with TMPSMX. The risk seems to be higher in patients with AIDS, elderly and concomitant use of diuretics. An 88-year-old female was admitted to the hospital because of malaise and progressive confusion, 3 days after starting TMP-SMX for urinary tract infection. On physical examination the patient was euvolemic and had no evidence of malignancy, renal, cardiac, adrenal, hepatic or thyroid disease. Laboratory tests results revealed hyponatremia, low serum osmolality, urine hyperosmolarity and an elevated urine sodium concentration, leading to the diagnosis of inappropriate secretion of antidiuretic hormone. TMP-SMX was discontinued and fluid restriction was instituted. The patient was discharged after serum sodium increased from $124 \mathrm{mmol} / \mathrm{L}$ to $134 \mathrm{mmol} / \mathrm{L}$. Two weeks after discharge the patient denied any malaise or confusion. TMP-SMX is very popular among elderly that presents with UTI. This paper is the first to emphasize this complication and the need of greater awareness among elderly population and suggest the sodium serum levels should be monitored closely during therapy with TMP-SMX.
\end{abstract}

Keywords: Trimethoprim-sulfamethoxazole; Syndrome; Inadequate $\mathrm{ADH}$ secretion

\section{Introduction}

Hyponatremia secondary to the syndrome of inappropriate secretion of antidiuretic hormone (SIADH) is an uncommon complication of treatment with trimethoprim-sulfamethoxazole (TMP-SMX). TMP-SMX acts as a K-sparing diuretic, if this is the case, hyponatremia would be inevitable [1,2].

\footnotetext{
Manuscript accepted for publication October 18, 2013

Department of Internal Medicine, Yale New Haven Hospital-SRC, New Haven, CT, USA. Email: maria.acuna@yale.edu

doi: http://dx.doi.org/10.14740/jmc1547w
}

Estimation of the occurrence of hyponatremia during TMPSMX is $26.4 \%$, which is more frequent than reported previously $[3,4]$. The risk of hyponatremia seems to be greatest in elderly population, other comorbidities and is dose dependent $[5,6]$. I described a case of an 88-year-old female who presents with malaise and confusion caused by TMP-SMX induced hyponatremia due to SIADH.

\section{Case Report}

This is an 88-year-old female presented to the emergency department with a 24-h history of malaise and progressive confusion. Three days prior to this admission, she had been started on TMP-SMX 800/160 mg twice a day for an urinary tract infection. The daughter reported that she became progressively confused and had difficulty performing simple tasks.

She has history of essential hypertension treated with lisinopril $10 \mathrm{mg}$ daily, coronary artery disease on metoprolol $25 \mathrm{mg}$ BID. The week before previous to her admission, she was feeling dizzy and with nauseas and was found to have an UTI, she was started on TMP-SMX and the day before to be hospitalized she had a follow-up at the adult primary care clinic where her sodium level was found to be normal $142 \mathrm{mmol} / \mathrm{L}$ (136 - $145 \mathrm{mmol} / \mathrm{L})$. Upon admission she was afebril but confuse with normal vital signs. She appeared euvolemic, with no signs of dehydration or congestion. Neurologic examination was normal except for general debilitation. Significant laboratory findings included sodium of 123 $\mathrm{mmol} / \mathrm{L}(136-145 \mathrm{mmol} / \mathrm{L})$, potassium of $4.2 \mathrm{mmol} / \mathrm{L}(3.5$ - $4.5 \mathrm{mmol} / \mathrm{L}$ ), chloride $100 \mathrm{mg} / \mathrm{dL}$ (98 - $106 \mathrm{mmol} / \mathrm{L}$ ), blood urea nitrogen of $19 \mathrm{mg} / \mathrm{dL}(6-19 \mathrm{mg} / \mathrm{dL})$, creatinine $1 \mathrm{mg} /$ $\mathrm{dL} \mu \mathrm{mol} / \mathrm{L}$ (0.6 - $1.2 \mathrm{mg} / \mathrm{dL})$, glucose of $106 \mathrm{mg} / \mathrm{dL}$ ( 70 - 100 $\mathrm{mg} / \mathrm{dL})$, a uric acid of $5 \mathrm{mg} / \mathrm{dL}(<7 \mathrm{mg} / \mathrm{dL})$ and a serum osmolarity of $256 \mathrm{mOsm} / \mathrm{L}$ ( 285 - $295 \mathrm{mOsm} / \mathrm{L})$. Urine sodium and urine osmolarity were elevated, $136 \mathrm{mEq} / \mathrm{L}$, and $470 \mathrm{mosm} / \mathrm{L}$, respectively. A CT of the head was normal. An AM cortisol level, thyroid-stimulating hormone (TSH) and free thyroxine levels were within normal limits. A TMPSMX pill count confirmed compliance with the drug regimen without evidence of overdose. 
The criteria for the syndrome of inappropriate secretion of ADH were fulfilled and other causes of SIADH were excluded.

On the day of admission, TMP-SMX was discontinued and the patient was treated with $1 \mathrm{~L}$ of intravenous $0.9 \%$ sodium chloride and ceftriaxone for UTI. Approximately 24 $\mathrm{h}$ after admission the patient's serum sodium decreased to $122 \mathrm{mmol} / \mathrm{L}$ (136 - $145 \mathrm{mmol} / \mathrm{L}$ ) and fluids were restricted to 1,200 mL/day. Her mental status improved over the next 48 $\mathrm{h}$ and she was discharged 4 days after her admission with a sodium level of $137 \mathrm{mmol} / \mathrm{L}(136-145 \mathrm{mmol} / \mathrm{L})$.

A follow-up sodium after 7 days of her discharge was $140 \mathrm{mmol} / \mathrm{L}$.

\section{Conclusions}

The present case reported emphasized the need for greater awareness of the development of this serious and potentially fatal complication in association with TMP-SMX therapy. This case has shown that the onset of TMP-SMX induced hyponatremia or SIADH ranges from the first days after the therapy has been started. Potential risk factors for SIADH due to TMP-SMX included advanced age, concomitant use of medications known to cause SIADH or hyponatremia, and possibly, higher TMP-SMX doses. Therefore, a high level of suspicion, close monitoring of serum sodium concentration particularly in elderly patients pretreatment may reduce the incidence of this serious and likely, rare, adverse effect.

\section{References}

1. Velazquez H, Perazella MA, Wright FS, Ellison DH. Renal mechanism of trimethoprim-induced hyperkalemia. Ann Intern Med. 1993;119(4):296-301.

2. Mori H, Kuroda Y, Imamura S, Toyoda A, Yoshida I, Kawakami M, Tabei K. Hyponatremia and/or hyperkalemia in patients treated with the standard dose of trimethoprim-sulfamethoxazole. Intern Med. 2003;42(8):665669.

3. Jick H, Derby LE. A large population-based follow-up study of trimethoprim-sulfamethoxazole, trimethoprim, and cephalexin for uncommon serious drug toxicity. Pharmacotherapy. 1995;15(4):428-432.

4. Smilack JD. Trimethoprim-sulfamethoxazole. Mayo Clin Proc. 1999;74(7):730-734.

5. Eiam-Ong S, Kurtzman NA, Sabatini S. Studies on the mechanism of trimethoprim-induced hyperkalemia. Kidney Int. 1996;49(5):1372-1378.

6. Fonseca PD, Moura TF, Ferreira KT. The effect of trimethoprim on sodium transport across the frog skin epithelium. Eur J Pharmacol. 1991;207(4):337-343. 